\title{
Findings from a Survey on Bus Stop Design
}

\author{
Kay Fitzpatrick \\ Dennis Perkinson \\ Kevin Hall \\ Texas Transportation Institute
}

\begin{abstract}
The bus stop is the first point of contact between the passenger and the bus service. The spacing, location, and design of bus stops significantly influence transit system performance and customer satisfaction. At present, relatively few transit agencies have comprehensive reference material available to assist in bus stop location and design. In recognition of the importance of bus stop location and design, the Transit Cooperative Research Program (TCRP) sponsored research to develop guidelines for locating and designing bus stops in various operating environments. These guidelines can assist transit agencies, local governments, and others (e.g., developers) in locating and designing bus stops that consider bus patrons' convenience, safety, and access to sites, as well as safe and efficient transit operations and traffic flow.

Mail-out surveys were conducted as part of the TCRP bus stop location and design guidelines project. The mail-out surveys, which were an initial task of the project, were used to determine current practices and areas of concern regarding bus stop design for transit agencies and states. Less than half of the responding transit agencies currently use guidelines or manuals, which indicates a need for the document being developed. Furthermore, almost every agency has moved a bus stop to improve
\end{abstract}


traffic operations and more than half have redesigned a curbside stop to a bus bay or nub design.

Transit agencies are typically responsible for establishing routes, stop spacing, stop location (near side, far side, or midblock), type of stop (curbside, bus bay, or nub), bus stop signs, and amenities (such as street furniture). Functions jointly shared by transit agencies and cities, counties, and states include selecting the length of the bus stop zone, selecting pavement design at bus stops, removal of parking for bus stops, bus stop relocation due to traffic, and bus priority measures. Selecting and maintaining traffic control devices is primarily a city function. The categories considered during the bus stop location and design process are (in descending order): bus operations, area type or land use, passenger safety, roadway features, and traffic conditions.

\section{Introduction}

The bus stop is the first point of contact between the passenger and the bus service. The spacing, location, and design of bus stops significantly influence transit system performance and customer satisfaction. At present, relatively few transit agencies have comprehensive reference material available to assist in bus stop location and design. In recognition of the importance of bus stop location and design, the Transit Cooperative Research Program (TCRP) sponsored research to develop guidelines for locating and designing bus stops in various operating environments. These guidelines can assist transit agencies, local governments, and others (e.g., developers) in locating and designing bus stops that are convenient and safe for patrons, offer efficient operation for bus operators, and provide for a smooth flow of traffic.

A review of the literature and existing transit agency manuals provided state-of-the-practice information. In addition, a mail-out survey was conducted of transit agencies and states because not all practices are available in published documents. The objective of the mail-out survey was to determine agency practices and concerns relating to bus stop location and design. This paper presents the findings from the mail-out survey. Interested readers are encouraged to con- 
sult the guidelines document (TCRP Report 19) and the unpublished final report for further information. (Both are available from the Transportation Research Board.) In addition, a summary of the complete study has been published in the May 1997 edition of ITE Journal.

\section{Survey Methodology}

To increase the likelihood that the surveys would be completed and returned, the research team developed a short and easy-to-complete survey. The team decided to have most of the questions on the survey answered by circling the correct response or by circling a number between 0 and 5 . The results from the survey were used to identify those agencies that could provide interesting and/or more detailed information in the phone surveys and/or site visits that were part of other tasks within TCRP Project A-10.

Certain aspects of bus stop operations, such as bus stop length, are available in agency publications. A request for the agency's current guidelines or manual was included in the surveys. The guidelines and/or manual provided information on the current state-of-the-practice in designing and locating bus stops. This allowed the research team to focus the survey on the identification of other issues and concerns.

Recognizing that states have a minimal role in bus operations when compared to transit agencies, the primary goals of the state survey were to (1) identify those elements in which states are heavily involved and (2) provide the opportunity for comments on the bus stop design and location process from a state's perspective. The state survey had a one-page, front-and-back format. Most of the questions were answered by circling the correct response or by providing a number between 0 and 3 .

The transit agency surveys were mailed to those agencies that submitted a 1992 Section 15 report. The survey was also sent to a selection of individuals identified from the Institute of Transportation Engineers (ITE) Transit Council and the Transportation Research Board (TRB) Bus Transit Systems and Intermodal Transfer Facilities committees. Of the 360 transit agency surveys mailed, 125 
were completed, for a response rate of 35 percent. The state survey was mailed to the 50 states, Puerto Rico, and the District of Columbia. Of the 52 state surveys mailed, 26 were completed, for a response rate of 50 percent. The following provides a section-by-section synopsis of the survey results and also notes significant findings.

\section{General Information}

The initial section of the survey provided an overview of certain elements within a transit agency or state, such as the use of guidelines and bus stop redesign or relocation experience.

\section{Use of Existing Guidelines}

In order to determine the current extent of guideline usage, the first question asked whether transit agencies use specific guidelines or a manual when they locate and design bus stops. Less than half ( 44 percent) of the responding transit agencies use guidelines or manuals, and two-thirds (65 percent) of the responding state agencies do not use guidelines or manuals. Publications were provided by 20 of the transit agencies responding to the survey, and an additional 11 provided information on the materials they use.

\section{Redesign and Relocation Experience}

A separate question asked about the extent and frequency of the redesign or relocation of existing bus stops. Almost every transit agency has moved a bus stop to improve traffic operations; however, only slightly more than half (58 percent) of the responding agencies have redesigned a curbside stop to a bus bay or nub design. (A bus bay is a specially constructed area off the normal roadway section provided for bus loading and unloading. It is also known as a turnout or duck out. Nubs are bus stops where the sidewalk is extended into the parking lane, which allows the bus to pick up passengers without leaving the travel lane. Nubs are also known as bus bulbs or curb extensions.) Half (50 percent) of the states have moved a bus stop to improve traffic operations, and just over onethird ( 38 percent) have redesigned a curbside stop to a bus bay or nub design. 
Approximately one-third ( 38 percent) of the states and 40 percent of the transit agencies have used bus priority measures such as restricted bus only lanes and signal pre-emption.

\section{Other Information}

Due to the emphasis in this project on high speed roadways, a question was included to determine whether the transit agency has bus stops located on roadways with an operating speed of $45 \mathrm{mph}$ or above. Approximately three-fourths of the agencies responded "yes" to this question. Other information requested included consideration of pavement requirements and the use of data bases to manage bus stop facilities. Special consideration for the pavement in bus stop and layover locations was provided by 60 percent of the respondents. Data bases are used to manage the bus stops by approximately 60 percent of the agencies.

\section{Bus Stop Configuration}

A separate section of the transit agency survey provided information on the frequency of use of different types of stops. The results show that both far-side and near-side stops are commonly used, while midblock stops are rarely used. The distribution of responses for the use of far-side and near-side stops are similar, which indicates that certain transit agencies prefer one type of stop over the other (and that the debate between which is better-far-side stops or near-side stops-will continue).

Nearly all of the transit agencies surveyed use curbside stops over the bus bay and/or nub design. With a value of 5 representing that the design is always used, 94 percent of the agencies marked either the 4 or the 5 value for curbside stops. For bus bays, 79 percent marked never (value of 1 ) or almost never (value of 2), while 94 percent marked similar answers for the nub design.

Transit agencies that use bus bays indicated that acceleration and deceleration lanes are rarely used in bus bay designs. Less than 25 percent of the respondents gave a 3 or higher response to this question. Clearly, the most common type of bus stop is the curbside stop; however, this survey along with field observations indicate that bus bay and nub designs are strongly considered and used. 


\section{Agency Roles and Responsibilities}

This section of the survey asked about agency roles and responsibilities in relation to a set of specific activities involved in bus stop placement and design. The questions were developed to determine the roles and responsibilities of the different agencies involved in bus stop placement and design. A scale of 3 to 0 was used to indicate the level of involvement, with 3 meaning that the agency was fully responsible for the function and 0 meaning that the agency had no involvement in the function.

The responses to the questions fall into three categories based on the allocation of agency responsibility: transit agency functions, joint functions (i.e., transit agency and city/county/state), and city/county/state functions. Each category is discussed separately.

\section{Transit Agency Functions}

Transit agency functions were classified as those elements where the transit agency responses (which are percentages) indicated a strong responsibility for that effort. The responses indicate that the transit agency is typically responsible for:

- route establishment

- stop spacing

- stop location (near side, far side, or midblock)

- type of stop (curbside, bus bay, or nub)

- bus stop signs

- amenities (such as street furniture)

The responses also indicate that these functions are typically coordinated with the city and/or county. Note that it is not possible to determine conclusively the level of coordination that exists between the transit agency and the city or county in any particular instance from the responses provided to these questions. Coordination, however, can be inferred when a high percentage of a given agency shows responsibility for a function and a high percentage of another agency shows responsibility or an input role on that function. 


\section{"Joint" Transit Agency and City/County Functions}

When the responses indicated that the city and the transit agency both have high responsibility or significant input, the element was classified as a joint effort. The determining characteristic of the percentages is the relative "balance" of the percentages between transit agencies and other public entities. The responses indicate that transit agencies and the city/county are "jointly" responsible for:

- selecting the length of the bus stop zone

- selecting pavement design at bus stops

- removing parking for bus stops

- relocating bus stops due to traffic

- determining bus priority measures

\section{City/County/State Functions}

When a city, county, or state was indicated as having the strongest responsibility for the element, it was placed into the city/county/state category. The responses indicate that selecting and maintaining traffic control devices is primarily a city function. Though, as in the case with the transit-agency-dominated functions, there appears to be some coordination with transit agencies.

\section{Key Factors}

The purpose of the Key Factors section of the survey was to identify the factors that are most important in three areas of bus stop location and design decisions. The three areas are (1) spacing between bus stops, (2) street-side elements for the stop (factors that influence bus operations that are associated with the roadway), and (3) curbside elements for the stop (factors that impact patron comfort, convenience, and safety that are located off the roadway). Respondents could select factors from a menu provided in the survey form (see Table 1), but were also free to express factors in different terms or identify new factors not on the menu. Consequently, approximately 140 different responses were provided for each of the three elements. 


\section{Table 1 \\ List of Possible Key Factors}

ADA access

Anticipated delay to major roadway vehicles

Anticipated delay to buses

Area type (retail, residential, suburban, etc.)

Auto parking availability

Headway (time between bus arrivals)

Neighborhood support positions

On-street parking

Passenger safety and security

Pavement design

\section{Pedestrian access}

Petition and/or complaints

Proximity to land uses

Ridership (boardings and alightings)

Route type (e.g., express, local, etc.)

Signal location and timing

Shoulder conditions

Traffic control devices

Traffic volume on roadway

Transfers (number of routes)

The following factors received a "number one priority" in terms of bus stop spacing decisions, street-side, and curbside design. (Numbers indicate the number of respondents assigning top priority to the factor.)

- Spacing Between Stops:

Area type (22)

Ridership (13)

Pedestrian access (10)

Route type (9)

Passenger safety (9)

- Street-Side Design:

Passenger safety (22)

ADA access (15)

Traffic volume (9)

- Curbside Design:

Ridership (24)

ADA access (24)

Safety (13)

Pedestrian access (9) 
In general, area type is far more important in the spacing/placement stage of stop design than in the later stages. Ridership is an important consideration both at the spacing stage and even more so in considering curbside aspects. Not unexpectedly, traffic operations factors are of greatest concern in considering street-side aspects of stop design. Safety and security were also important. ADA considerations are particularly important in curbside and street-side decisions. Public input and furniture issues were of least importance in location and design decisions at any of the stages.

\section{Additional Comments}

At the end of the survey instrument, concerns and comments were solicited, and space was provided for their inclusion. Since any information provided was entirely optional and totally unstructured, the responses were diverse.

Of particular interest were comments suggesting several areas to avoid in developing bus stop location and design guidelines. One common theme was the caution to avoid too structured a final document. There was concern that bus stop decisions are very site specific and do not lend themselves to too much formalization. The research team was urged to maintain flexibility in the developed guidelines. Another expression of the same idea involved cautioning the project team not to try to determine whether far-side or near-side stops were better.

At the transit agency level, several transit agency respondents specifically mentioned their need for help with meeting ADA requirements, either in gaining a better understanding of exactly what is required, an interest in learning what others are doing, or concerns over the magnitude of the challenge of ADA compliance.

At the state level, several states responded that they had no control over any issue listed or that bus stop design is handled by the transit authority with local government coordination. Other states assist with design only if the design is a part of a state highway project, or they issue permits or participate in the bus stop design if it is on a state route or is part of a grant project. Several states re- 
sponded that their roles regarding transit are in transition, and that they are revising their design process and standards to include transit plans in the early stages in order to acquire the necessary right-of-way to include bus stops. States are also expanding their roles to support local planning and include transit needs.

\section{Conclusion}

The mail-out survey provided insight into the types of bus stop configurations used by transit agencies and what factors are considered when making busstop related decisions. This knowledge assisted in the development of guidelines that are to be used when making bus stop design and location decisions. Most bus-stop related functions are either the joint responsibility between agencies or one agency actively provides supporting information to the responsible agency. Because of this interaction, a single set of guidelines was developed to be usable to both a transit agency and a city, county, or state agency. The single document discusses the items that are important to each group, while also enabling an agency to see those elements considered by other agencies when making similar decisions. *

\section{References}

Fitzpatrick, K, K. Hall, D. Perkinson, R. L. Nowlin, and R. Koppa. 1996. Guidelines for the Location and Design of Bus Stops. TCRP Report 19.

Fitzpatrick, K., K. Hall, D. Perkinson, R. L. Nowlin, and R. Koppa. 1996. Location and Design of Bus Stops, Final Report. Unpublished TCRP Report, July.

\section{Acknowledgments and Disclaimer}

The work reported in this paper was conducted under sponsorship of the Transit Cooperative Research Program. The TCRP technical panel director for this study was Dianne Schwager. Her support, along with that of the technical advisory panel, is appreciated.

The contents of this paper reflect the views of the authors who are responsible for the opinions, findings, and conclusions presented herein. The contents do not necessarily reflect the official views or policies of the Transit Cooperative Research Program. 


\section{About the Authors}

Kay Firzpatrick, Ph.D., P.E., is an Associate Research Engineer and the Program Manager of the Traffic Analysis Program for the Texas Transportation Institute. Her degrees are from Texas A\&M University and Penn State University. Dr. Fitzpatrick was the principal investigator for the TCRP project and was responsible for the traffic engineering portion of the research study.

Dennis G. Perkinson is currently an Assistant Research Scientist with the Texas Transportation Institute. He holds undergraduate and graduate degrees in sociology from the University of South Florida and an M.S. in transportation from Northwestern University. Mr. Perkinson was responsible for the transit-related aspects of the TCRP bus stop study.

Kevin Hall is an Assistant Research Scientist at the Texas Transportation Institute. He received a Bachelor of Landscape Architecture from Virginia Polytechnic Institute and State University and a Master of Urban and Regional Planning from Texas A\&M University. Mr. Hall's focus on the TCRP study was those factors relating to pedestrians and elements located off the roadway. 